\title{
RELACIÓN COGNOSCITIVA, PROCESO DE CONOCIMIENTO Y VERDAD
}

\author{
... Mientras se expulsa ostensiblemente a la gran fi- \\ losofía por la gran puerta del espíritu, se cuelan por la \\ puerta trasera estrechos prejuicios de clase, provincianos \\ y regionales que dominan el pensamiento del historiador, \\ aunque sea sólo semiconscientemente. \\ Charles A. Beard, Written History as an. Act of Faith
}

De acuerdo con los antiguos, la filosofía tiene su origen en el asombro (thaumazein) que el hombre siente ante los enigmas del mundo circundante. Desde este punto de vista, la historia (no en el sentido de res gestae, sino en el de historia rerum gestarum) es necesariamente una fuente fecunda que invitit a filosofar, y se vincula estrechamente con la filosofía, sean cuales fueren las pretensiones de los historiadores que se atienen al positivismo.

Para demostrarlo baste mencionar, a titulo de ejemplo, las divergencias con que diversos historiadores presentan el mismo suceso, de acuerdo con los periodos o generaciones a que pertenecen, o, si son contemporáneos, de acuerdo con el sistema de valores del que parten y los criterios de valoración relacionados con él. Este sistema emana de los diversos intereses de clase o de grupo, de las distintas concepciones del mundo, etc... Pero el asunto que nos ocupa rebasa este tipo de situaciones. Se trata de un problema mucho más vasto y profundo, puesto que concierne a la historia de la ciencia en su conjunto y absolutamente a todas las obras de algún valor en esta materia. Son precisamente estas obras las que aquí nos interesan: no los trabajos históricos escritos con fines de propaganda, sino las obras estrictamente científicas, las que sin lugar a duda alcanzan el nivel de competencia relativo al periodo en cuestión.

Frente a estas obras surge el "asombro" que fecunda el pensamiento filosófico: a su respecto se imponen insistentemente preguntas cuya respuesta exige reflexiones metateóricas, reflexiones filosóficas.

Muy a pesar de sus métodos y técnicas de investigación tan adelantadas, los historiadores no solamente presentan valoraciones e interpretaciones distintas a propósito de las mismas cuestiones y los mismos hechos, sino que seleccionan y presentan los hechos de modo muy diverso. ¿No podrá decirse entonces, que los historiadores hacen en realidad propaganda disfrazada, en lugar de practicar la ciencia?

Pero si puede admitirse la probidad subjetiva de los científicos y de sus esfuerzos intelectuales, cpodrá suponerse que sea Clío la musa de las artes y 
no de la ciencia, que la historia pertenezca, entonces, a las artes y no se le puedan aplicar criterios científicos?

Admitamos que, a consecuencia del largo debate que sobre esta materia se ha desarrollado, nosotros nos inclinamos a defender el carácter científico de la historia, como lo hacen los historiadores profesionales quienes se han rebelado solidariamente contra toda "insinuación artística". Ahora bien, dadas las diferencias notorias en la manera de concebir los mismos sucesos por los historiadores según las épocas si son contemporáneos o según representen a tal o cual clase, etc., dado que cada generación se siente casi obligada a reescribir la historia, ¿podemos admitir que la historia tenga la capacidad de transmitir la verdad objetiva acerca de aquello que constituye el objeto de sus estudios?

El elemento subjetivo del conocimiento histórico ha llegado a ser tan evidente que sólo pueden negarlo los conservadores de antiguallas positivistas y no los científicos que representan el nivel de la ciencia actual. ¿Quiere esto decir que la historia no cumple con el postulado de la objetividad del conocimiento científico, y que, en consecuencia, no tiene carácter científico?

A pesar de las objeciones y declaraciones relativas a la "inocencia" filosófica de la ciencia histórica con las que no dejan de colmarnos los representantes del positivismo, todavía muy numerosos en este dominio de la ciencia, estas cuestiones y el "asombro" teórico que implican, nos han conducido directamente al recinto mismo de la filosofía.

En su tiempo, Engels previno a los que se dedican a las ciencias naturales contra todo intento positivista de negar el papel de la filosofía en este dominio de la investigación. Quien lo hiciera, según Engels, caería en la peor de las filosofías: una amalgama de recuerdos de conocimientos escolares y de opiniones corrientes, a la moda en un momento dado. En efecto: es imposible eliminar la filosofía de estos razonamientos y por eso, puesta en la puerta, la filosofía se cuela por la ventana. $A$ fortiori, y por las más diversas razones, esta prevención vale para la historia.

Todos los filosofos que practican la reflexión metateórica en este dominio se lamentan del hecho de que se subestime a la filosoffa en la ciencia de la historia. Esto es por otra parte muy comprensible, sobre todo desde un punto de vista psicológico. Es muy raro, por el contrario, mucho más raro, que estas cuestiones sean tratadas por los historiadores profesionales.

Por esto, nunca podrán apreciarse demasiado declaraciones tales como las del eminente historiador y teórico de la historia inglés, E. H. Carr:

Las ideas liberales del siglo xIx sobre la historia son muy afines a la doctrina económica del laisser-faire y son también el producto de una concepción serena y segura del mundo. Que cada quien se ocupe de sus propios asuntos y una mano invisible velará por la armonía universal. Los acontecimientos 
históricos constituyen una demostración del hecho supremo de un progreso in. finito, benéfico y visible, hacia cuestiones más elevadas.

Era el siglo de la inocencia y los historiadores se paseaban por los jardines del Paraíso, sin una brizna de filosofía con que cubrirse, desnudos y sin temor alguno ante el Dios de la historia. Más tarde, conocimos el Pecado y la Caída, y los historiadores que hoy se jactan de poder prescindir de la filosofía están en realidad embarcados a sabiendas en una empresa tan vana como la de quienes en una colonia nudista de suburbio intentan recrear los jardines del $\mathbf{P a}$ raiso. 1

H. J. Marrou, historiador y teórico de la cultura francesa, expresa el mismo pensamiento en otros términos, más categórica y violentamente:

Hay que acabar con estos inveterados reflejos y sacudirse la modorra en la que el positivismo ha mantenido durante un tiempo demasiado largo a los historiadores (al igual que, por otro lado, a sus colegas de las ciencias "exactas"). Nuestro oficio es pesado y abrumador por las servidumbres técnicas; tiende a la larga a desarrollar en el práctico una mentalidad de insecto especializado. En vez de ayudar a reaccionar contra esta deformación profesional, el positivismo daba al científico una buena conciencia ("yo no soy más que un historiador, de ningún modo un filósofo...") ... Hay que denunciar airadamente semejante disposición de espéritu ya que constituye uno de los peligros más graves que pesan sobre el porvenir de nuestra civilización occidental, amenazada de zozobrar en una terrible barbarie técnica.

Parodiando la máxima platónica, inscribiremos en el frontón de nuestros Propileos: "Nadie entre aquí si no es filósofo", si no ha reflexionado primero sobre la naturaleza de la historia y la condición del historiador: la salud de una disciplina cientifica exige, por lo que se refiere al hombre de ciencia, cierta inquietud metodológica, una preocupación por tomar conciencia del mecanismo de su comportamiento y cierto esfuerzo reflexivo con respecto a los problemas "gnoseológicos" implicados por este.2

Pero sin duda alguna, ha sido Charles A. Beard, historiador y teórico norteamericano, formado en la escuela del presentismo, quien ha expresado esta idea en términos más catégoricos. Las palabras de Benedetto Croce que cita coinciden con la advertencia de Engels a los especialistas en ciencias "exactas":

...Toda selección y disposición de los hechos correspondientes a un gran dominio de la historia, local o universal, de raza o de clase, se halla determinada inexorablemente por un sistema de referencia en la mente de aquel que efectúa semejante selección y disposición. Este sistema de referencia abarca las cosas que parecen necesarias, así como las que parecen posibles y deseables. Puede tratarse de un sistema amplio fundado en un conocimiento e iluminado por una vasta experiencia; pero también puede ser estrecho, mal informado y nada esclarecido. Puede ser una gran concepción de la historia o simplemente una aglomeración de elementos confusos. Pero se encuentra en la mente; de un

1 E. H. Carr, What is History? Ed. MacMillan, Londres, 1962, p. 14.

2 H. J. Marrou, De la connaissance historique, Ed. du Seuil, París, 1959, pp. 10-11. 
modo inexorable. Con relación a Croce, puede decirse que mientras se expulsa ostensiblemente a la gran filosofía por la gran puerta del espiritu, se cuelan por la puerta trasera estrechos prejuicios de clase, provincianos y regionales que dominan el pensamiento del historiador, aunque sea sólo semiconscientemente. ${ }^{3}$

Estos ejemplos tomados de la literatura histórica no marxista (ya que la literatura marxista, basada deliberadamente en el materialismo histórico, presenta un cuadro diferente), bastan para ilustrar las tesis que nos interesan. Es cierto que, como ya lo hemos dicho, son mucho más numerosas las declaraciones sobre esta materia de los filósofos que han reflexionado teóricamente sobre la ciencia de la historia; pero por razones ya señaladas son menos características, aunque no menos interesantes e instructivas. A título de ejemplo, me limitaré a mencionar una sola entre muchas de ellas: la de Ernest Nagel. Sus palabras son tanto más preciosas para nosotros cuanto que nos conducen directamente al corazón mismo de lo que nos preocupa en nuestro trabajo: la objetividad del conocimiento histórico.

Al igual que los demás trabajadores intelectuales, los historiadores profesionales raras veces tienen conciencia de los factores que organizan los conceptos o. de los principios que sirven para evaluar el material que utilizan habitualmente en su disciplina. Los historiadores han escrito mucho acerca de las técnicas especializadas de su oficio, así como de los problemas generales relacionados con la crítica interior o exterior de los documentos y otras huellas del pasado. No obstante, las discusiones serias sobre cuestiones tales como la extructura de la explicación histórica, su garantía y, en particular, la lógica de los nexos causales en la investigación histórica, han sido sostenidas principalmente por filósofos profesionales o por investigadores que razonan filosóficamente en otras ramas de las ciencias sociales. Cuando.los historiadores se pronuncian sobre problemas de este tipo (generalmente, con motivo de alguna ceremonia) no hacen más que repetir de buen grado las ideas filosóficas que les fueron inculcadas por azar en el curso de sus estudios o de sus lecturas fortuitas, y que rara vez han sometido a crítica a la luz de su propia práctica profesional. Sea como sea, esta hipótesis les ayuda a explicar el escepticismo general (o el "relativismo") profesado por muchos historiadores contemporáneos con respecto a la posibilidad de un conocimiento objetivo en su disciplina, pese a que en sus análisis históricos concretos no practican lo que predican. ${ }^{4}$

La situación puede resumirse en pocas palabras: la problemática teórica y metodológica de la ciencia histórica (que debe distinguirse de la técnica de investigación) ha preocupado principalmente a los filósofos y pocas veces a los historiadores; es muy frecuente el caso del historiador positivista que

$3 \mathrm{Ch}$. A. Beard, "Written History as an Act of Faith", The American Historical Review, 1934, vol. XXXIX, p. 227 (el subrayado es mío).

4 E. Nagel, "Relativism and Some Problems of Working Historians", en Sidney Hook (ed.): Philosophy and History, New York University Press, 1963, p. 76. 
deliberadamente deja a un lado esta problemática. De aquí que la importancia y responsabilidad de los trabajos filosóficos en esta materia esté creciendo notablemente, a pesar de las honrosas opiniones de muchos historiadores y de sus deseos. Porque si no se puede rechazar la filosofía de la ciencia de la historia y si, por el contrario -como dice Raymond Aron, y en cierta interpretación de su observación yo estoy plenamente de acuerdo con él- "La teoría precede a la historia"; 5 si los historiadores se nutren de migajas de las teorías filosóficas corrientes, la filosofía es, entonces, la primera responsable de la confusión teórica que impera entre los historiadores, particularmente cuando se trata de problemas fronterizos entre la historia y la filosofía. Puede encontrarse un ejemplo clásico en el problema que nos interesa aqui, el de la objetividad del conocimiento y de la verdad en la ciencia de la historia, problema filosófico por excelencia, en el que la teoría tradicional del conocimiento ha contribuido principalmente a sembrar la confusión. Se hace indispensable una reflexión filosófica consciente y crítica para llegar a resolver la complicada problemática, teórica y metodológica, de la ciencia de la historia. Así, pues, por ella comenzaremos.

\section{1) Los tres modelos del proceso de conocimiento}

No importa que los historiadores -al igual que los cultivadores de otras ciencias- sean conscientes de ello o no, o que reconozcan o no la función de la filosofía en su disciplina; el hecho es que sus ideas sobre el proceso de conocimiento y, por consiguiente, sobre el problema de la verdad, tienen su raíz en la filosofía. Aún más: han sido impuestas por las ideas filosóficas dominantes en este campo y la responsabilidad de ello incumbe en primer lugar, como ya se ha dicho antes, a la filosofía.

Dado que en filosofía no se admite el rechazo natural de los textos superados, la bibliografía existente acerca del análisis filosófico del proceso del conocimiento y de sus productos - que constituye lo que Ilamamos "teoría del conocimiento" - es tan grande que es ya insuficiente la vida de un individuo para agotarla. De igual manera puede admitirse que todas las "ideas nuevas", con mayor o menor desarrollo, han aparecido ya en esta bibliografia. En estas circunstancias, dos procedimientos se presentan a nuestra elección: podemos tratar de sumergirnos en el océano de la erudición e intentar la exposición de nuestro saber al gran público, lo cual será, sin duda, ocasión para la ostentación de nuestros conocimientos, pero no añadirá nada al problema mismo aparte de hacerlo más pesado y aburrido. También podemos renunciar al deseo de envanecernos con esa erudición superficial y decir simplemente lo que tenemos que decir sobre el tema en cuestión. Por supuesto que de esta forma correríamos el riesgo de privarnos de una decora-

\footnotetext{
5 R. Aron, Introduction a la Philosophie de l'Histoire, Gallimard, Paris, 1948, p. 99.
} 
ción muy apreciada en ciertos medios intelectuales, y, lo que es más importante, nos privaríamos de la posibilidad de rendir homenaje a todos aquellos con quienes hemos contraído una deuda de reconocimiento científico por haberles tomado ideas, de una manera o de otra. Puesto que deliberadamente me decido por la segunda vía, comenzaré por declarar que los elementos de aquello que diré acerca del proceso del conocimiento y de sus productos, y que considero como una presuposición indispensable para los razonamientos ulteriores en este artículo, han sido expuestos muchas veces y bajo aspectos diversos, en la bibliografía de esta materia. Siendo esto notorio es totalmente inútil cargar la exposición para hacer ostentación de erudición y de citas. En estas circunstancias, la única originalidad a la que puede aspirar el autor es la forma en la que reunirá en un todo elementos ya conocidos y la forma en que usará ese todo en sus razonamientos.

Comencemos, pues, por los tres elementos tradicionales de todo análisis del proceso del conocimiento - con la reserva, por supuesto, de la terminología diferenciada-: el sujeto cognoscente, el objeto del conocimiento, y el saber, producto del conocimiento. A sabiendas hacemos aquí abstracción del aspecto psicológico del problema, de modo que no nos apegaremos al acto del conocimiento, para concentrarnos únicamente en la problemática gnoseológica.

Por pedantería pura añadamos simplemente que la indole y la problemática filosófica de cada uno de los términos mencionados, "sujeto", "objeto" y "conocimiento" son complejas pero que, dado el cuadro general que aqú nos hemos fijado, no tendremos que desarrollarlos más adelante. Nos bastará admitir por conocidas ciertas intuiciones cognoscitivas de esos términos. Volveremos, sin embargo, a uno de ellos, al "sujeto cognoscente", y no para hacer explicaciones semánticas sino por razones de fondo. Por el momento, hic et nunc, interesémonos en esta tríada del proceso del conocimiento, solamente desde el punto de vista de la tipología de las relaciones que intervienen entre sus elementos. Distinguiré tres modelos fundamentales del proceso del conocimiento - teóricamente, como se verá más adelante, hay más, si se toma en cuenta la multiplicidad de las combinaciones posibles de sus componentes.

Si por el proceso del conocimiento entendemos una interacción particular entre el sujeto y el objeto del conocimiento, cuyo resultado es el producto intelectual que llamamos conocimiento, la interpretación de esta interacción puede hacerse en el marco de una gran diversidad de modelos teóricos. Esta tipología no es en modo alguno especulativa: todos estos modelos han tenido una ilustración concreta en tendencias filosóficas que se han dibujado en el curso de la historia.

El primer modelo ha estado en la base del concepto mecanicista de la teoría del reflejo y consiste en lo siguiente: el objeto del conocimiento actúa 
sobre el aparato perceptivo del sujeto que, según este modelo, es un elemento pasivo, contemplativo y receptivo. El producto de este proceso, el conocimiento, el saber, es el reflejo, la copia del objeto, y la génesis de este reflejo reside en la influencia mecánica ejercida por el objeto sobre el sujeto. Este modelo puede ser considerado mecanicista.

Este modelo, como ya hemos dicho, ha aparecido efectivamente en la historia del pensamiento filosófico, y a partir de allí se ha extendido a todos los dominios de la investigación. En cierto sentido, es un modelo clásico, tanto por la frecuencia con la que se ha presentado cuanto por su larga historia: se remonta por lo menos a la teoría de Demócrito sobre los "eidola" y continúa hasta el sensualismo moderno y el empirismo trascendente. Es clásico, también, porque históricamente está ligado a lo que llamamos la definición clásica de la verdad, en la cual debía encontrar fundamento teórico la siguiente tesis acerca de la verdad: es verdadero el juicio que estatuye alguna cosa sobre el objeto del conocimiento y este objeto es verdaderamente como el juicio lo enuncia. Sin la teoría del reflejo (cuya interpretación no es necesariamente mecanicista y simplificada), la definición clásica de la verdad es, en efecto, indefensible en forma consecuente.

El primer modelo es, pues, un modelo en el cual, como se ha dicho, el sujeto es un elemento pasivo, contemplativo y receptivo de la relación cognoscitiva; su papel es el de instrumento que registra los impulsos que vienen del exterior, podría decirse que su papel es semejante al de un espejo, si se le compara a la percepción visual. Las diferencias que aparecen en la imagen de la realidad de distintos observadores, provienen de las diferencias individuales o cualitativas de su aparato perceptivo.

Popper llama, de manera metafísica, a esta teoría del proceso del conocimiento "teoría del conocimiento-recipiente" (eine Kübeltheorie des Bewusstseins). ${ }^{6}$ Históricamente, esta teorfa aparece vinculada, en primer lugar, a las escuelas materialistas, que presuponen la admisión de la realidad del objeto del conocimiento, al igual que una interpretación sensualista-empírica de la relación cognoscitiva. Si en la teoría del conocimiento la visión materialista del mundo ayuda a percibir y comprender el elemento objetivo de la relación cognoscitiva, ya que pone el acento sobre este elemento objetivo precisamente, entorpece, en cambio (sin llegar a impedirla en ningún caso), la percepción y la comprensión del elemento subjetivo de esta relación. Marx no hizo sino comprobar un hecho notorio al escribir en sus tesis sobre Feuerbach (I), que todo el materialismo pasado consideraba la realidad bajo la forma de objeto y no como actividad concreta humana; el aspecto activo fue desarrollado por el idealismo, aunque no perfectamente, ya que lo estudió sólo en forma abstracta.

Si en el primer modelo, el modelo pasivo-contemplativo, se otorga al

G K. R. Popper, Die offene Gesellschaft und ihre Feinde, Berna, 1958, t. II, p. 262. 
objeto la primacía en la relación sujeto-objeto, en el segundo modelo (que es su opuesto y que puede llamarse idealista-activista), la primacía si no exclusividad la tiene el sujeto cognoscente. Según este modelo, el objeto es creado por el sujeto, es su producto. En el curso de la historia, este modelo reaparece en diversidad de filosofías subjetivo-idealistas y -n su estado puro- en el solipsismo.

Marx, acabamos de recordarlo, veía la superioridad del idealismo sobre el materialismo pre-marxista en lo que el idealismo había desarrollado del aspecto activo, lo que concierne, obviamente, también al conocimiento humano. Esto resulta evidente si se considera el segundo modelo de la relación cognoscitiva que concentra la atención en el sujeto y llega a atribuirle el papel de creador de la realidad. Si en este modelo - en contra de lo que prueba la experiencia - el objeto del conocimiento desaparece, se hace sobresalir al papel del sujeto en el proceso del conocimiento. Esto confirma una vez más la tesis psicológica, según la cual es el punto de vista desde el que se observa y se reflexiona el que determina que se concentre la atención en tal o cual aspecto de la realidad.

En los razonamientos epistemológicos de K. Mannheim, contenidos en su Ideologie und Utopie, encontramos un bellísimo análisis de este retorno al sujeto y con ello al factor subjetivo en el proceso del conocimiento, lo que caracteriza al segundo modelo. Bajo una clara influencia de Marx y del marxismo, Mannheim subraya el papel de los dos factores a este respecto: el disgregamiento del sistema social tradicional y con él el de la concepción del mundo, al igual que la oposición, a fines del medievo y comienzos de los tiempos modernos, al principio de autoridad, para lo cual se tomaba como punto de partida y fundamento, al individuo y su existencia. ${ }^{7}$ Todo depende, sin embargo, de la manera como se conciba e interprete a este individuo. ${ }^{8}$

Con la problemática del individuo, a la que volveremos más adelante, abordamos el tercer modelo. Se caracteriza por el hecho de que, al principio de la preponderancia de uno de los elementos de la relación cognoscitiva -del elemento objetivo (primer modelo) o del elemento subjetivo (segundo modelo)-, se opone el principio de su interacción. Se rechaza, pues, el mo delo mecanicista del conocimiento que convierte al sujeto en un mero contemplador que registra pasivamente; se subraya el papel activo del sujeto que está condicionado en forma distinta, pero siempre socialmente, y que aporta al conocimiento la manera peculiar de ver la realidad que le ha transmitido la sociedad. Pero se rechaza también, con no menor energía, el modelo activista-subjetivo del idealismo, ya que en él se pierde místicamente el objeto del conocimiento que existe objetivamente, y no queda nada más en el campo de batalla que el sujeto cognoscente y sus productos. Pero, en

7 K. Mannheim, Ideologie und Utopie, Frankfurt, 1952, pp. $13^{s s .}$

8 Ibid., pp. 26 ss. 
compensación, se admite el modelo de la relación cognoscitiva en el cual tanto el sujeto como el objeto conservan una existencia objetiva y real, al mismo tiempo que ejercen al uno sobre el otro una influencia mutua, todo esto dentro del marco de una teorfa del reflejo modificada desde el punto de vista activista. Esto sucede en el marco de la práctica social del sujeto que conoce al objeto en el curso de su acción. Este modelo del proceso del conocimiento, en favor del cual me pronuncio personalmente, se concretiza en la teoría del reflejo interpretada convenientemente, que ha desarrollado la filosofía marxista.

Es evidente que nuestra elección en esta materia conlleva consecuencias importantes cuyo alcance abarca a la totalidad de nuestra actitud cientifica, y en particular nuestra concepción de la verdad. Hasta aquí nos hemos limitado a realizar una tipologia enumerativa. Ahora debemos justificar nuestra elección y, por tanto, debemos desarrollar las categorías que entran en juego. Sin embargo, antes de emprender la exposición positiva de nuestras opiniones a este respecto, debemos explicar, sucintamente al menos, por qué nos hemos limitado a una categoría dada de modelos rechazando las demás a limine.

Respondamos primero la cuestión de si puede haber y si hay otros modelos de la relación cognoscitiva fuera de los que hemos hablado. La respuesta es, obviamente, afirmativa. Como ejemplo pueden citarse las diversas variantes del modelo dualista: el modelo fundado en la concepción de Leibniz de la armonía preestablecida, el modelo sustentado en el ocasionalismo, etc. ¿Por qué no han despertado nuestro interés estos modelos? Simplemente porque, dado su carácter anticientifico, es decir místico, no solamente carecen en nuestra época de todo valor heurístico, sino que, además, son incapaces de mover el ánimo de los investigadores contemporáneos.

Pero volvamos al problema real, al análisis y desenvolvimiento del modelo, escogido por nosotros, de la teoría del reflejo interpretada de manera activista.

También en este modelo la relación cognoscitiva es una relación entre el sujeto y el objeto, y esto es evidente. Porque si fuese retirado uno de los eslabones, la relación dejaría de existir. La elección de un modelo del proceso de conocimiento está ligada indisolublemente a la concepción del mundo a partir de la cual se efectúa. Para un materialista, por tanto, es indudable que existe el objeto del conocimiento, estimulante exterior de las impresiones resentidas por el sujeto cognoscente, que existe objetivamente, es decir, fuera del sujeto cognoscente e independientemente de él. Según los materialistas que admiten el tercer modelo de la relación cognoscitiva, solamente pueden negar la tesis ontológica relativa a la existencia del objeto del conocimiento aquellos que se comprometan con el callejón sin salida de la especulación filosbfica, contradiciendo necesariamente con su propia práctica lo que proclama su teo- 
ría. Pero si bien acentúa claramente la importancia del eslabón objetivo en la relación cognoscitiva (sólo con el fin de acentuarla, he repetido algunas tesis en realidad banales desde el punto de vista del materialismo), el partidario del tercer modelo de la relación cognoscitiva ve en el sujeto el eslabón principal. Esto se sigue directamente de la introducción del factor antropológico en la teoría del conocimiento. Pero esto exige una explicitación y una interpretación.

El concepto que se.coloca en el primer plano es el del individuo, que constituye comprobadamente no sólo el problema de una filosofía del hombre, en forma autónoma, sino el problema de toda investigación en la que el hombre tenga un papel esencial en tanto que individuo concreto actuante.

Es evidente que cuando hablamos de la relación cognoscitiva como relación cuyos términos son el sujeto cognoscente y el objeto del conocimiento, mucho depende -si no todo- del sentido que demos a la expresión "sujeto cognoscente". Las ideas aquí presentes son, por un lado, la concepción individualista-subjetivista y, por el otro, la concepción socio-objetiva.

La primera se vincula generalmente, en los tiempos modernos, a la caída del antiguo orden económico y social. Durante el tránsito de una formación a otra, desaparece el sentimiento de vínculo entre el individuo y la sociedad, lo que produce, en consecuencia, la incomprensión del papel de la sociedad en la formación del individuo. Karl Mannheim, como ya lo he dicho, trata esta materia en forma interesantísima. Tiene una fuerte influencia de Marx no solamente en lo relativo al problema del condicionamiento social de las opiniones y actitudes del hombre, sino en lo que respecta al concepto del individuo en tanto que individuo social. Con todo y que en la bibliografía de esta materia pase generalmente inadvertida esta segunda influencia, tal vez sea más importante que la primera, Mannheim diçe que no hay por qué asombrarse frente al hecho de que la nueva concepción del individuo y la comprensión de su condicionamiento social se hayan manifestado en el momento en que se comenzaron a sentir claramente los efectos del orden social individualista, al borde de la anarquía. ${ }^{9}$

9 "La ficción del individuo aislado que se basta a sí mismo se encuentra, bajo fornas muy diversas, en el fundamento de la teoria individualista del conocimiento y de la psicología genética... Las dos teorias fueron engendradas por el individualismo teórico exagerado ( $y$, por tanto, especialmente en la época del Renacimiento y del liberalismo individualista). Pero este individualismo no pudo aparecer sino en una situación social en la que se había perdido de vista el vinculo primario del individuo con el grupo. En situaciones de este tipo, el papel que la sociedad desempeña en la formación del individuo escapa a la atención del observador.

Y esto llega a ser tan decisivo que se intentan explicar las características más frecuentes, obviamente determinadas por la comunidad de vida y de relaciones entre los individuos, a partir de la naturaleza primitiva del individuo o del plasma embrionario... Y no se debe esto al acaso, como tampoco el hecho de que el punto de vista sociológico haya podido agregarse a los demás métodos relativamente tarde. Tampoco es gratuito que se haya podido percibir el vínculo entre sociedad y conocimiento sólo hasta el momento en 
De acuerdo con el concepto individualista-subjetivista, el individuo es independiente de la sociedad y de su influencia. En otros términos, es independiente de la cultura y por este hecho se le regresa a su existencia biologica, que determina en forma natural sus características y propiedades. Contra las apariencias, este concepto, lejos de elevar el rango del individuo-sujeto en el proceso del conocimiento, lo rebaja. Es este concepto, también, lo que conduce a la construcción mecanicista, pasiva y contemplativa del modelo de la relación cognoscitiva. $\mathrm{El}$ individuo está condicionado biológicamente e introduce este condicionamiento en el proceso del conocimiento vía su aparato perceptor. El sujeto no tiene, por otra parte, sino una existencia que registra y transforma en cierta forma los impulsos que le llegan del mundo exterior.

El error reside, en primer lugar, en esta muy peculiar construcción del individuo y, en segundo lugar, en el hecho de que se conciba al conocimiento como contemplación y no como acto. Así, los falsos presupuestos determinan no solamente la construcción del modelo de la relación cognoscitiva, sino que también prejuzgan la solución del problema que constituye el objeto de la investigación: ¿cómo se realiza el proceso del conocimiento en tanto que relación entre sujeto y objeto?

Estos dos presupuestos equivocados han sido atacados en muchas ocasiones y desde distintos puntos de vista. Es, empero, indudable que Karl Marx no sólo fue el primero en el tiempo, en relación a tendencias concurrentes, sino también que su forma sistemática de abordar el problema e introducir la concepción nueva es muy superior a las demás. Para ilustrar las opiniones de Marx en esta materia, me referiré primordialmente a las Tesis sobre Feuerbach, con todo y que se encuentran más desarrolladas en la Ideologia alemana y en otras obras anteriores o posteriores.

Si lo hago es porque considero las Tesis sobre Feuerbach una obra genial (conviene recordar que se trata de la obra de un autor joven, ya que tenía apenas 27 años). Bajo la forma de tesis relativas a la crítica de la filosofía de Feuerbach, esta obra contiene los grandes rasgos de una nueva filosofía, propia del autor. Para poder comprender y apreciar las Tesis -aunque sea solamente debido a lo compendiado de la obra- es necesario conocer bien tanto la filosofía en general cuanto la filosofía de Marx en particular. Las Tesis no ofrecen una lectura fácil, lo que no reduce en nada el gran valor de la obra, como lo saben muy bien los filósofos profesionales contemporáneos, aunque no sea sino gracias al ejemplo de la interpretación $y^{\cdot}$ la importancia del Tractatus de L. Wittgenstein.

En su tesis VI, Marx expresa, a propósito del concepto de ser humano,

que la humanidad despliega de nuevo sus esfuerzos para oponer a una tendencia de la sociedad individualista no dirigida, que llega hasta la anarquía, un tipo de orden social más orgánico". K. Mannheim, Ideologie und Utopie, Frankfurt, 1952, pp. 26-30. 
algunas ideas propiamente revolucionarias: tanto porque constituyen una critica profunda de la antropologia filosófica de L. Feuerbach, representativa de la época, cuanto porque poseen los fundamentos de una nueva antropología, marxista, que ha conservado todo su valor y actualidad aún hasta nuestros días, y esto no solamente en el ámbito de la filosofía marxista.

He puesto estas ideas por fundamento de mi concepción de individuo, concepción que considero marxista tanto por su génesis (puesto que se sigue de ideas expuestas expressis verbis por Marx mismo), cuanto por su conformidad con las otras tesis de la concepción marxista del mundo. Las ideas a que me refiero son las siguientes:

el ser humano es, en su realidad, el conjunto de las relaciones sociales; si se hace abstracción de este carácter social del individuo, el único vínculo que permanece entre los seres humanos es el de la naturaleza, lo cual es falso.

He aquí precisamente la cuestión: ¿es el individuo solamente un ejemplar de cierta especie biológica, ejemplar ligado a sus semejantes únicamente en forma natural, biológica? A la luz de la ciencia contemporánea responderemos negativamente: es obvio que el ser humano es un individuo biologico en cuanto es un ejemplar de la especie homo sapiens, pero esto no basta para caracterizar al hombre, puesto que además de las determinantes biológicas, está formado por determinantes sociales y es precisamente por eso por lo que es un individuo social. Marx lo expresa metafóricamente diciendo que el individuo es "el conjunto de las relaciones sociales".

Lejos de mil la idea de hacer abstracción del condicionamiento natural (biológico) del individuo y de su personalidad, es decir, del conjunto de ideas, actitudes y disposiciones inherentes al individuo real. El hombre pertenece al mundo animal, tanto por sus crigenes cuanto en la actualidad. No podríamos omitir ahora lo que ya vefa claramente Feuerbach (por ejemplo, en su antropología): que el hombre en cuanto parte de la naturaleza está 'sujeto a sus leyes generales. Esta omisión sería tan inadmisible ahora como en esos tiempos, dado que nuestro conocimiento en lo que respecta al condicionamiento biológico o bioquímico del individuo es ahora incomparablemente mayor. Hablamos del código genético, circunscribimos cada vez más el fondo de este asunto al llegar a explicar el papel de los ácidos nucleicos (DNA y RNA) en el mecanismo de la herencia, lo que nos acerca peligrosamente al momento en que la intervención bioquímica permita tener ingerencia en el dominio de la personalidad humana. Dije "peligrosamente" porque si se llega a descifrar el enigma del código genético, al grado de poder intervenir prácticamente en su estructura, la humanidad tendría a su disposición un poder cuya importancia en las relaciones humanas, rebasaría, en cierto sentido, la del poder que ha traido el desciframiento de la energía atómica, tanto desde el punto de vista de sus efectos positivos cuanto consi- 
derando los negativos para la humanidad. Sea como sea, cuando se estudian en nuestros tiempos los problemas del hombre, no se puede desdeñar el aspecto "natural" del problema; bien por el contrario, la importancia y significación de este aspecto crece continuamente.

Pero esto en nada reduce el alcance de las determinantes sociales del individuo. Aun si se otorga su justo valor a las determinantes naturales y a la extensión de nuestros conocimientos en esta materia, no deja de ser cierto que el hombre, de manera cualitativamente diferente del resto del mundo animal, está sujeto a la influencia de la cultura y es el producto tanto del desarrollo de la naturaleza, cuanto del desenvolvimiento de la sociedad. Más aún: si se le retira de este contexto cultural y social, tampoco se puede comprender al individuo desde el punto de vista de las determinantes naturales, dado que estas determinantes son el producto de un desarrollo sujeto a la influencia del factor social y se acerca el momento en que después de haber profundizado las leyes estructurales del código genético, la humanidad se pondrá por objetivo profundizar igualmente sus leyes dinámicas, para descubrir cómo se constituye el código genético. En este momento, el factor social y cultural penetrará, sin duda, en el dominio de la naturaleza.

De todas formas, sólo teniendo en cuenta este aspecto de la cuestión puede plantearse el problema del "hombre" en una forma que no sea abstracta, es decir, del hombre no sólo en tanto que ejemplar de cierta especie biológica, sino de manera concreta, social, es decir, teniendo en cuenta sus características históricas de grupo e individuales. ${ }^{10}$

Sólo comprendido así, como individuo concreto tanto por su condicionamiento biológico como social, puede el individuo ser sujeto en la relación cognoscitiva. Es evidente, en consecuencia, que el carácter de esta relación no es ni puede ser pasivo, que el sujeto está siempre activo en ella, que introduce y debe introducir necesariamente en el proceso del conocimiento alguna cosa que proviene de él. El proceso del conocimiento cuenta siempre con el sujeto y el objeto; por esta razón es un proceso subjetivo-objetivo, en una acepción determinada de estos términos.

¿Qué es, pues, este sujeto en la relación cognoscitiva? Ciertamente no es sólo un aparato perceptivo biologicamente condicionado que no hace otra cosa sino registrar los impulsos provenientes del exterior, por más que el sujeto deba necesariamente poseer un aparato perceptivo. Lo que es decisivo es precisamente otra cosa: aquello que diferencia al hombre del animal y que se manifiesta en su aptitud para absorber cultura, es el hecho de que es a la vez producto y productor de cultura. No tratamos de establecer aquí el origen de esta aptitud cultural ni lo que la determina. Admitimos el proceso

10 Me he ocupado más extensamente de estos problemas en el capitulo "La conception marxiste de l'individu" de mi obra Le marxisme et l'individu, Ed. Armand Colin, París, 1968, pp. 61-116. 
como dado y lo que nos preocupa son, por el contrario, sus efectos en el proceso del conocimiento.

El hecho de que el hombre, el sujeto, sea "el conjunto de las relaciones sociales" conlleva efectos diversos, también, en el dominio del conocimiento. La articulación dada al mundo, para comenzar, es decir la manera de percibir, de distinguir partes determinadas, la dinámica de las percepciones, etc., se liga al lenguaje y a su aparato conceptual, que el sujeto cognoscente recibe de la sociedad a través de la educación en tanto que transmisión de la experiencia acumulada en la filogénesis social, 11 a través del condicionamiento social de sus juicios según el carácter de clase o de grupo de los sistemas de valores admitidos. Esto ha sido desarrollado de manera particularmente clara por el marxismo y, después, por la sociología del conocimiento. No deben dejarse de tomar en cuenta todos los demás factores biológicos y sociales que, en la ontogénesis del individuo, determinan su psiquismo, su conciencia y su subconciencia, asunto que trata la psicología moderna, en particular la llamada psicología profunda. Tales son las direcciones principales, si no todas, de la investigación sobre los factores determinantes del sujeto cognoscente y de su comportamiento, investigaciones que obligan a rechazar radicalmente el modelo pasivo y mecanicista de la relación cognoscitiva. El sujeto cognoscente no es un espejo, no es un aparato que registra pasivamente los impulsos que le llegan del exterior. Más bien, por el contrario, es precisamente la fuerza que hace marchar este aparato, que lo regula convenientemente y que transforma, a su manera, los datos que el aparato le proporciona. Alguien escribió con toda razón que los que comparan el conocimiento a la fotografía de la realidad olvidan, entre otras cosas, que la cámara fotográfica registra aquello hacia lo cual ha sido dirigida por el ojo y la mano del fotógrafo. $\mathbf{Y}$ es por esto por lo qué las imágenes obtenidas difieren las unas de las otras.

El sujeto cognoscente "fotografía" la realidad con ayuda de un mecanismo socialmente formado que domina el "ojo" de este aparato. Pero además, "transforma" las informaciones recogidas según un código complicado de condicionamientos sociales que se introducen en el psiquismo del sujeto a través del lenguaje, gracias al cual piensa el sujeto, a través de su situación de clase y de los intereses de grupo al que pertenece, a través de motivaciones conscientes y subconscientes y, sobre todo, a través de su acción social sin la cual el conocimiento es una ficción especulativa.

$\mathrm{Y}$ a este respecto procede explicar otra idea revolucionaria del marxismo acerca del conocimiento y del sujeto cognoscente. Se trata de la categoría de la práctica en el conocimiento humano.

En las Tesis ya citadas, Marx escribe:

11 Ver A. Schaff: Jezyk a poznanie ("El lenguaje y el conocimiento"), Varsovia, 1964. 
El principal defecto de todo materialismo pasado -incluso el de Feuerbach- es que el objeto, la realidad y el mundo sensible, no son considerados sino bajo la forma de objeto o de intuición (Anschauung), y no como actividad concreta humana, como práctica, no en forma subjetiva... (Tesis I).

Feuerbach, descontento con el pensamiento abstracto, recurre a la percepción sensible, pero no considera la sensibilidad como actividad práctica del sentido del hombre (Tesis V).

De la rica problemática de la praxis en Marx, aun si nos limitamos a la forma en que aparece en las Tesis sobre Feuerbach, separaremos un fragmento decisivo en este contexto. Se trata, en especial, del papel de la práctica en el proceso del conocimiento, de la importancia de esta categoría en el concepto de sujeto cognoscente.

Nos hemos esforzado más arriba por demostrar el papel activo del sujeto en el proceso del conocimiento al referirnos al condicionamiento social del sujeto, al sujeto en tanto que "conjunto de relaciones sociales". Se trataba de probar que el sujeto no era un aparato registrador pasivo, sino que aportaba al conocimiento un factor subjetivo, determinado por su condicionamiento social. Esto explica las diferencias no sólo en la apreciación y la interpretación, sino aun en la percepción (la articulación) y la descripción de la realidad, diferencias que marcan el conocimiento de los sujetos en diversas épocas históricas y aun en la misma época, pero en distintos medios sociales (étnicos, de clase, etc.). Sin embargo, el carácter activo del sujeto cognoscente se halla vinculado primordialmente al hecho de que el hombre conoce actuando, hecho que pasa generalmente inadvertido en los razonamientos abstractos sobre el conocimiento. Ésta era la idea que Marx reprochaba a Feuerbach, el no considerar la sensibilidad como actividad práctica, es decir, como actividad transformadora de la realidad percibida. Es característico que Marx llame a esta forma de entender la sensibilidad como actividad práctica "actividad de los sentidos del hombre" considerándola claramente un rasgo específico (Tesis V). Es igualmente de aqui de donde vienen sus reproches a "todo el materialismo pasado"; la realidad y el objeto no se consideran actividad concreta humana, como práctica, y por esto el materialismo no. parte del papel activo del sujeto y, en este sentido, de manera subjetiva.

Si se quiere descifrar y entender el tercer modelo, activista, de la relación cognoscitiva es necesario tomar en cuenta dos elementos: la idea particular del individuo como individuo social, y la consideración del conocimiento como actividad práctica de los sentidos. Este modelo, como ya lo hemos dicho, está ligado orgánicamente con la teoría del reflejo interpretada en forma activista - única interpretación que concuerda con el sistema de filosofía marxista.

La teoría del reflejo puede interpretarse de dos maneras: con el espíritu del modelo mecanicista de la relación cognoscitiva (el primero de nuestra 
tipología), es decir, teniendo al proceso del conocimiento por pasivo y contemplativo, o bien de acuerdo con el espíritu del modelo objetivo activista de la relación cognoscitiva (el tercero de nuestra tipología), es decir, teniendo al conocimiento por una acción de los sentidos.

Pese a todas las diferencias que hay entre estos dos modelos de la relación cognoscitiva, ambos se inscriben dentro del marco de la teoría del reflejo en sentido amplio, si bien, obviamente, interpretada en forma distinta en los dos casos. Hay, especialmente en los dos casos, elementos que permiten cierta concepción del conocimiento, contrariamente al segundo modelo (idealistaactivista); se puede, por esta razón, usar a su respecto un mismo nombre que los agrupe: "la teoría del reflejo". Estos elementos comunes son los que siguen:

En primer lugar, el reconocimiento de la existencia objetiva del objeto del conocimiento, es decir, de su existencia fuera de todo espíritu cognoscente e independientemente de él. Es una concepción materialista desde el punto de vista de la teoría del conocimiento. Esto pone en franca oposición la teoría del reflejo en sus diversas interpretaciones, con toda concepción subjetivo-idealista del proceso del conocimiento.

En segundo lugar, el reconocimiento de que el objeto del conocimiento, que existe objetivamente, es la fuente exterior de la percepción de los sentidos, sin los cuales el proceso del conocimiento sería imposible. Ésta es una consecuencia del realismo en teoría del conocimiento y del materialismo en ontología.

En tercer lugar, el reconocimiento del hecho de que el proceso del conocimiento constituye una relación particular entre el sujeto que existe objetivamente y el objeto real, y que, por tanto, es una relación sujetoobjeto.

$Y$, por fin, en cuarto lugar, el reconocimiento del hecho de que el conocimiento del objeto es accesible $y$, por tanto, que en contradicción con todo agnosticismo, en el proceso del conocimiento la "cosa en si" se convierte en "la cosa para nosotros".

Estos cuatro puntos bastan para probar la importancia de los elementos comunes a las diversas variantes de la teoría del reflejo que, a pesar de sus diferencias internas, se oponen solidariamente al idealismo y al agnosticismo. Lo puntos tercero ý cuarto, en particular, explican la aparición de la palabra "reflejo" en el nombre de la teoría que, históricamente, se formó tanto en la lucha contra el agnosticismo (particularmente kantiano), cuanto en la lucha contra el idealismo.

Esta comunidad de fundamentos no excluye divergencias en la interpretación de la teoría del reflejo. Más bien, por el contrario - ya lo hemos dicho-, estas divergencias aparecieron, de hecho, en el curso de la historia. Intentemos agruparlas como sigue: 
En primer lugar, se trata de la concepción del sujeto cognoscente que si bien todos los representantes de la teoría del reflejo piensan que existe objetivamente, posee para unos un carácter pasivo, receptivo y para otros tiene un carácter activo.

En segundo lugar, algunos consideran como individuo al sujeto cognoscente, mientras que otros le dan el carácter de individuo social, producto de determinantes sociales.

En tercer lugar, si bien las teorías del reflejo están de acuerdo en cuanto al hecho de que el proceso del conocimiento es subjetivo-objetivo, pueden diferir en la interpretación de esta subjetividad del proceso, lo cual está estrechamente ligado no sólo al concepto de sujeto, sino también al sentido que se confiera al conocimiento mismo: para unos, es un proceso pasivo y contemplativo, para los demás se trata de un proceso activo y práctico.

$Y$, por fin, en cuarto lugar, tenemos que si todas las teorías del reflejo están de acuerdo en la tesis según la cual el conocimiento del objeto es áccesible, esto no impide, de ninguna manera, que surjan diferencias de interpretación acerca de la forma de lograr este conocimiento: es un acto realizado de un solo golpe, o bien se trata de un proceso infinito. Esto no impide tampoco que surjan divergencias en cuanto al producto del proceso del conocimiento: para algunos se trata de copias, y, por tanto, de un reflejo fiel (realismo ingenuo: el objeto es tal que llega al conocimiento de los sentidos y las cualidades se encuentran en los objetos mismos); para otros, el conocimiento es el reflejo de la realidad en el espíritu (realismo crítico: la imagen de la realidad en el espíritu no es arbitraria, es el reflejo de esta realidad, y por eso permite la acción efectiva, pero no es una copia perfecta, lo que, por otra parte, está contradicho por la tesis según la cual el conocimiento es un proceso).

Dijimos más arriba que la versión activista de la teoría del reflejo, vinculada al tercer modelo de la relación cognoscitiva, era la única que coincidía con el conjunto del sistema de la filosofía marxista. Entiendo esto de dos maneras: en primer lugar en el sentido directo, es decir, que sólo esta concepción puede ser incluida sin contradicción en el sistema de las otras tesis fundamentales de la filosofía marxista; en segundo lugar, que este concepto de la teoría del reflejo puede ser reconstituido a partir de enunciados de Marx, Engels y Lenin. Dado que el estudio de la teoría marxista del reflejo rebasa el marco de lo que nos preocupa en este estudio, pero que, por otra parte, algunos de sus elementos nos serán útiles en el curso de nuestros razonamientos, me limitaré a presentarle en forma sucinta. Mencionaré, al mismo tiempo, que en la literatura marxista se encuentran a este respecto simplificaciones que se atienen al espíritu del modelo mecanicista de la relación cognoscitiva. Si se trata del estudio más detallado del problema, y partiendo 
obviamente de las posiciones que yo mismo defiendo, me permitiré remitir al lector a obras anteriores que he escrito a este respecto. ${ }^{12}$

Hay principalmente tres factores, tres componentes de la filosofía marxista militante, en favor de la aceptación de la variante activista del modelo de relación cognościtiva y del rechazo del modelo mecanicista:

En primer lugar, el concepto marxista del individuo en cuanto "conjunto de las relaciones sociales"..

En segundo lugar, el hecho de que para Marx el conocimiento es una actividad práctica, es decir, una actividad de los sentidos.

En tercer lugar, el concepto según el cual el conocimiento verdadero es un proceso infinito tendiente a la verdad absoluta al reunir las verdades relativas.

Si se quieren respetar estas tesis de la filosofía marxista, y cada una de ellas tiene en el sistema de esta filosofía un papel esencial, es necesario admitir el modelo objetivo-realista de la relación cognoscitiva que se une a ellas para formar un todo orgánico.

¿Cómo se presenta, a la luz de lo que precede, el problema de la objetividad del conocimiento?

Establezcamos, para comenzar, nuestra acepción del adjetivo "objetivo" que califica el "conocimiento".

Basta consultar cualquier diccionario filosófico para ver hasta qué punto es equívoco el término, toma los sentidos más diversos, aun contradictorios, según los autores y, para empeorar las cosas, según las épocas. En tales situaciones, la única salida consiste en proponer una definición que, respetando lo más posible el sentido establecido del término, sus intuiciones corrientes en la bibliografía de la materia, deberá empero precisar el sentido de la palabra bajo la propia responsabilidad del autor. En este caso distingo tres acepciones del término "objetivo" que nos interesarán en ulteriores razonamientos.

"Objetivo" significa, en primer lugar, aquello que se sigue del objeto, En este sentido, "el conocimiento objetivo" es el conocimiento que refleja en el espíritu (en una determinada acepción del verbo "refleja") el objeto que existe fuera del espíritu cognoscente e independientemente de él. El conocimiento subjetivo, en oposición al conocimiento objetivo, seria el conocimiento proclamado por ciertas tendencias filosóficas (el idealismo subjetivo), que crearía su objetivo y no lo reflejaría.

En segundo lugar, la palabra "objetivo" -en relación con el conocimiento y el espíritu cognoscente- toma el sentido de "válido para todos".

12 A. Schaff, "Algunos problemas de la teoría marxista de la verdad" (Niektóre zagadnienia marksistowskiej teorii prawdy), $2^{\text {a }}$ ed., Varsovia, 1959, pp. 47-65; "El lenguaje y el conocimiento" (Jezyk a poznanie), capítulo "Lenguaje y realidad" (Jezyk a rzeczywistosc); ensayo VI, "L'objectivité de la connaissance à la lumière de la science et de la philosophie du langage", en Langage et connaissance, Ed. Anthropos, Paris, 1969 . 
Por tanto, el "conocimiento objetivo" es un conocimiento de alcance general, y no sólo individual (en oposición al conocimiento "subjetivo").

$Y$, por fin, en tercer lugar, la palabra "objetivo" significa "independientemente de los elementos emotivos y de la parcialidad que conllevan". De acuerdo con esto "subjetivo" significaría "teñido de elementos emotivos" y "parcial".

Después de haber intentado precisar el sentido de los términos "objetivo" y "subjetivo" cuando se refieren al conocimiento, nos plantearemos el problema de saber cómo se presenta el postulado de la objetividad del conocimiento en el contexto de los diversos modelos de la relación cognoscitiva. $\mathrm{Y}$, en particular, si se puede hablar de conocimiento objetivo en el modelo objetivo-activista (el tercero).

La solución de este problema es la siguiente:

En él marco de cada una de las variantes de la teoría del reflejo (es decir en el marco del primero y tercer modelo), se puede hablar de objetividad del conocimiento en el primer sentido del término "objetivo" que hemos distinguido.

Pero decir esto es banal. Lo que nos interesa, primordialmente, es la objetividad en el segundo y tercer sentido. Presuponemos que se trata del conocimiento científico, practicado de manera competente y con la intención de descubrir la verdad objetiva.

Se puede hablar de la objetividad del conocimiento en el sentido de que su valor, su importancia, no es sólo individual, sino general: ¿puede hablarse de la objetividad del conocimiento en el sentido de que es independiente de todo elemento emotivo y de toda parcialidad, si se presupone al mismo tiempo que el sujeto cognoscente, en cuanto producto de relaciones sociales, tiene un papel activo en el proceso del conocimiento e introduce siempre elementos ligados de una cierta forma al sujeto y, en consecuencia, elementos subjetivos?

Sí y no. - Todo depende de nuestra acepción de la expresión "conocimiento objetivo"; sí, si no la hacemos absoluta; no, si la concebimos con categorías absolutas.

Comencemos por la objetividad en el sentido que excluye la parcialidad y los elementos emotivos. Si no se ha excluido por presuposición el papel activo del sujeto en el conocimiento, el conocimiento no se encuentra, evidentemente, libre de elementos emotivos, no es del todo imparcial. ¿Qué significa, pues, "objetividad" en este caso? Equivale al postulado según el cual deben eliminarse al máximo en el proceso del conocimiento todo elemento emotivo y toda parcialidad que ejerza sobre el conocimiento verdadero una influencia deformadora. La "objetividad", en esta acepción, está teñida de subjetividad, puesto que no podría jamás ser absoluta, sino humana, relativa. En este sentido, la "objetividad" es siempre relativa (este co- 
nocimiento es más objetivo que este otro), nunca absoluta; constituye siempre un proceso "en devenir".

Si se admite el papel activo del sujeto en el proceso del conocimiento $y$, por tanto, el hecho de que necesariamente el sujeto introduce en el cono cimiento un factor subjetivo, resulta evidente que la "objetividad" en el sentido de que el conocimiento es válido para todos y no solamente para un individuo o un grupo, no puede significar que su valor sea el mismo para todo el mundo, que toda diferencia entre sujetos cognoscentes desaparezca, y que nos encontremos frente a la verdad absoluta. También a este respecto, encontramos que no se trata de un estado terminado, completo, sino de cierta tendencia, de cierto proceso. De nuevo tenemos una característica relativa y no absoluta (tal conocimiento se admite más generalmente que tal otro, lo cual, por otra parte, no coincide con su criterio de verdad).

Así, pues, dado el papel activo del sujeto en el proceso del conocimiento, la "objetividad" en la segunda y tercera acepción de nuestra clasificación no es sino relativamente lo propio del conocimiento: tanto en el sentido de que se trata de una propiedad que no puede discutirse sino por comparación entre los productos de los diversos procesos del conocimiento, cuanto en el sentido de que nos las habemos siempre con un proceso y no con un estado de cosas terminado y definitivo.

El carácter del proceso del conocimiento científico y sus productos es, pues, siempre objetivo-subjetivo. Objetivo tanto porque se refiere al objeto que se refleja de alguna manera en è conocimiento, cuanto por el carácter relativo del valor general de este conocimiento y la eliminación de los elementos emotivos que empapan al conocimiento. Pero es subjetivo en el sentido más general, dado el papel activo que cumple el sujeto en el proceso del conocimiento.

Después de haber comprobado que el factor subjetivo aparece siempre en el conocimiento, conviene preguntarse qué relaciones tiene con el factor objetivo-social. Como ya he tratado este problema en otro estudio, ${ }^{13} \mathrm{me} \mathrm{limi-}$ taré a resumir las ideas principales.

En términos generales puede decirse que por factor subjetivo entendemos aquello que el sujeto cognoscente aporta al proceso del conocimiento. Esto difiere de la acepción tradicional de la expresión "factor subjetivo". No se trata, en efecto, de un elemento del conocimiento desligado del objeto del cual constituye cierto reflejo, puesto que el subjetivismo asi entendido es, en nuestra opinión, una ficción especulativa. Tampoco se trata de opiniones individuales opuestas a las ideas admitidas en general, porque como lo hemos dicho más arriba, el límite entre estas opiniones varía, para no referirnos al

13 Véase A Schaff, "L'objectivité de la connaissance à la lumière de la sociologie de la connaissance et de l'analyse du langage" en Langage et connaissance, Ed. Anthropos, París, 196g. 
engaño deliberado que se practica con fines de propaganda. De lo que en realidad se trata, por el contrario, es del papel activo del sujeto en el proceso del conocimiento, de su influencia en la formación de este proceso y de sus resultados a través de los factores que determinan el psiquismo y la actitud del sujeto. Estos factores son, entre otros, la estructura del aparato perceptivo del sujeto; el lenguaje mediante el cual y en el marco del cual piensa el sujeto, el lenguaje que lo provee de una suerte de aparato conceptual que determina una articulación y una percepción dada de la realidad; los intereses de clase o de grupo que contribuyen a decidir la elección de un sistema de valores por los individuos pertenecientes a esas clases, a esos grupos, etc.

Lo que llamamos aquí "factores subjetivos", por ser la emanación del sujeto en el proceso del conocimiento (hablamos metafóricamente), no tiene carácter individual subjetivo tal como aparece en los razonamientos tradicionales, sino, por el contrario, tiene carácter objetivo-social. Porque la génesis de todos los ejemplos de "factor subjetivo" que hemos mencionado más arriba es social y su carácter es social. Esto se muestra con evidencia cuando hablamos del lenguaje que nos transmite la sociedad por medio de la educación en tanto que producto terminado y aparato de nuestro pensamiento. Resulta también evidente cuando hablamos de las determinantes sociales (étnicas, de clase, de grupo), del psiquismo y de las actitudes del sujeto, particularmente cuando se trata del sistema de valores y juicios, y, por tanto, cuando hablamos de los factores determinantes que constituyen el objeto de las investigaciones de la antropología cultural, de la sociología del conocimiento, etc. Pero la cuestión no es tan evidente cuando nos referimos a la estructura del aparato perceptivo cuya influencia sobre el conjunto del proceso del conocimiento es indiscutiblemente notoria (por más que las funciones del pensamiento no coincidan con la función de la percepción de los sentidos) y muy individual. Sin embargo, esta misma estructura, genéticamente hablando, se deriva también de fuentes sociales y tiene, por esta razón, un carácter objetivo-social.

¿Por qué hablamos aquí del "factor subjetivo"? Porque está vinculado orgánicamente al sujeto cognoscente entendido como "el conjunto de las relaciones sociales". Así entendido, el "factor subjetivo" es de carácter objetivo-social y no idealista-subjetivo. Pero ésta es una cuestión de concepción y de interpretación.

De esta forma hemos dado término a nuestras reflexiones sobre el modelo de la relación cognoscitiva. Estas reflexiones nos han conducido directamente al problema de la verdad y del conocimiento verdadero. 
2) La verdad como proceso

El problema que nos interesa, el problema de la objetividad de la verdad histórica, nos obliga a detenernos no sólo en el problema del modelo de la relación cognoscitiva, sino también en el de la verdad, al hacer las reflexiones epistemológicas preliminares.

Porque es la verdad lo que nos preocupará en lo que sigue, la verdad con respecto al conocimiento histórico, y esto constituye un problema típicamente filosófico. Una vez más se ve qué tan frágiles son los fundamentos de la aversión que experimentan los historiadores con respecto a la filosofía; los hechos prueban que en la ciencia de la historia, como en todas las demás ciencias, por otra parte, nos encontramos frente a problemas filosóficos por excelencia y que, por tanto, no pueden ser resueltos sin recurrir al patrimonio de la filosofía. Es imposible, en efecto, eliminar de nuestro lenguaje palabras tales como "verdad", y basta intentar el examen del problema de la verdad para darse cuenta de que se trata, con toda evidencia, de un problema filosófico. Se puede, obviamente, intentar una solución personal, sin recurrir a la filosofía como disciplina científica, pero con ello lo único que se logra es hacer a un lado a la filosofía. Sin embargo, la indole del problemá no se modificará $y$, además, al no tomar en cuenta el trabajo efectuado en un dominio dado, se corre el riesgo o bien de redescubrir América hace ya mucho descubierta, o lo que es peor, de deçir tonterías.

Al hablar del problema de la verdad introduciremos algunas definiciones y precisaremos algunas opiniones, de manera que quede claro el punto de vista desde el que habremos de examinar la cuestión. Nos limitaremos a retomar, sucintamente, cuestiones que ya he tratado en otra parte, ${ }^{14}$ pero las abordaremos en una forma nueva, directamente en relación con el problema de la verdad absoluta y relativa, así como también el de la verdad total y parcial.

Comencemos por puntualizar algunas cosas: cuando utilicemos el término "verdad" entenderemos "juicio verdadero" o "frase verdadera". Para no adentrarnos en una discusión sobre la verdad de normas, juicios y otros tipos de enunciado que no constituyen frases atributivas, delimitaremos claramente nuestra acepción del término "verdad".

Si se trata, en cambio, de definir "juicio verdadero", adoptaremos la definición clásica de la verdad: es verdadero el juicio cuya aserción se comprueba conforme a la realidad. Es fácil de advertir que la teoría clásica corre parejas con la teoría del reflejo y que, de todas formas, los dos conceptos están ligados orgánicamente: si se admite la posición clásica de la teoría de la verdad no se puede rechazar la teoría del reflejo, y recíproca-

14 Véase Adam Schaff, $Z$ zagadnień marksistowskiej teorii prawdy ('Problemas de la teoría marxista de la verdad"), $2^{2}$. ed., Varsovia, 1959. 
mente. Más aún, estos dos conceptos se complementan y se presuponen mu. tuamente desde el punto de vista teórico.

Como es sabido, la definición clásica de la verdad es una de las muchas definiciones que aparecen en la bibliografía de la materia. Ciertas dificultades teóricas determinan el rechazo de la definición clásica, que, sin em. bargo, parece dictada por el buen sentido. Son también dificultades teóricas las que determinan a algunos, por una $\mathbf{u}$ otra razón, a preferir otra definición -si bien conservan generalmente a la primera en su repertorio. Comenzando por la explicación de lo que se entiende por "realidad" y pasando por la explicación de la reláción entre el juicio y la realidad (adequatio para algunos, correspondencia, reflejo, concordancia, parecido, copia, etc., para otros), de la relación característica para la "verdad", todo es aquí problemático y es objeto de acerbas diferencias entre las diversas escuelas filosóficas. No es, pues, únicamente por razones de doctrina, con todo y que éstas tienen también su papel, sino igualmente con objeto de evitar algunas dificultades teóricas, por lo que se ha intentado establecer de formas distintas una definición de la verdad más simple y más fácilmente concebible, por ejemplo: acuerdo general, coherencia con el sistema, utilidad práctica, economía de pensamiento, etc., es decir, conformidad con algún criterio aceptado de verdad. Sin embargo, no se podría admitir ninguna de estas definiciones sin que esto trajera por consecuencia el rechazo de la teoría del reflejo con todas las implicaciones filosóficas que conlleva. Es, por otra parte, evidente, que ninguno de los criterios arriba mencionados (acuerdo general, coherencia, etc.), garantiza la verdad del conocimiento en el sentido de que, cuando enunciamos algunas cosas con fundamento en estos criterios, podamos estar seguros de que nuestras aserciones se conforman a la realidad.

$\mathrm{Si}$, pues, en cualquier ciencia y en particular en la ciencia de la historia, afirmamos que nuestro juicio es verdadero, entendemos por esto que estamos persuadidos de que es así, en la realidad, camo nosotros juzgamos (y por tanto, de que disponemos de pruebas cientificas en apoyo de nuestras aserciones). Ésta es la posición de la definición clásica de la verdad que cada uno de nosotros admite en su acción, casi por intuición. Rechazamos, por tanto, cualquier otra definición de la verdad, cualquier definición concurrente. Esto no quiere decir que no nos sirvamos en forma auxiliar de los criterios que proponen en nuestras investigaciones acerca de la verdad. El acuerdo general, la concordancia con el sistema, la utilidad práctica, tienen un papel que desempeñar en nuestros razonamientos y constituyen argumentos que obligan a una reflexión complementaria con respecto a ciertas proposiciones dadas; pero es a esto a lo que se reduce el problema.

¿Cómo se presenta, a estas luces, el problema de la verdad? Si nos atenemos a la definición clásica de la verdad, intentar calificar de objetiva a la verdad es un pleonasmo. Porque no puede haber otra verdad que la 
verdad objetiva, tanto en el sentido de que se trata de un juicio relativo a la realidad objetiva, cuanto en el de que la relación cognoscitiva misma es objetiva, en la acepción que le hemos conferido más arriba (primer y tercer modelo. de esta relación). Lo contrario de la verdad objetiva sería la verdad subjetiva, pero de acuerdo con la definición clásica de la verdad, la expresión "verdad subjetiva", es en sí misma contradictoria. La verdad subjetiva así entendida es una falsedad. Así, pues, toda verdad es objetiva y resulta por ello inútil hablar de verdad objetiva para distinguirla de otras verdades. La expresión "verdad objetiva", si bien es un pleonasmo, puede, sin embargo, conservar su utilidad para subrayar la objetividad de la relación cognoscitiva; con mayor razón si esta expresión ha sido empleada tradicionalmente en la bibliografía de esta materia.

Es, por el contrario, muy complicado distinguir las verdades absolutas y relativas, lo mismo que sus consecuencias para la comprensión del proceso del conocimiento.

E1 viejo pleito entre absolutismo y relativismo esconde dos problemas diversos, si bien ligados entre sí: el primero toma la forma de un desacuerdo entre los partidarios de la verdad absoluta, entendida en el sentido de que el juicio en cuestión es verdadero o falso con independencia de las circunstancias, es decir, de la persona que lo enuncia, del momento y del lugar, y los partidarios del punto de vista opuesto, que defienden la tesis según la cual el carácter verdadero o falso del juicio (de la aserción) sí depende de las circunstancias en que se enuncia; el segundo, por el contrario, toma la forma de un desacuerdo en cuanto a que las verdades que aparecen en el conocimiento humano tienen un carácter total (entero) o parcial.

En el primer aspecto del desacuerdo (propio del relativismo tradicional), el partidario de la teoría del reflejo no ve ningún inconveniente en rechazar un relativismo de tendencia claramente subjetivista, para dar razón a sus adversarios absolutistas. ¿Qué argumentos oponen estos últimos a los relativistas que pretenden que un enunciado dado es verdadero o falso según la persona, el tiempo o el lugar? Dicen, con justa razón -y uno de los representantes más eminentes de esta opinión ha sido Kazimierz Twardowski ${ }^{15}$ que los argumentos de los relativistas provienen de malentendidos vinculados con el uso de términos equívocos (tales como "yo", "ahora", "aqui"), lo mismo que de enunciados elípticos, es decir, de enunciados en los que no se precisa exactamente la persona, el lugar, el tiempo de la acción (v. gr.: "las aceitunas son suculentas", "llueve hoy", "aqui hace calor"). La apariencia de que la verdad del enunciado varía con el sujeto, el lugar y el tiempo, es el efecto de un equivoco, puesto que debido a los términos empleados, los enunciados

15 Cf. K. Twardowski, "O tak zwanych prawdach względnych", en Rozprawy $i$ artykuly filozoficzne ("A propósito de lo que llamamos verdades relativas" en Estudios y artículos filosóficos), Lvov, 1927. 
resultan indeterminados (elípticos). Basta eliminar la elipsis, precisando los enunciados, para que el equívoco desaparezca. Si en lugar de decir "las aceitunas son suculentas" se dice: "Para mí (definiendo la persona), las aceitunas son suculentas"; si en lugar de decir "llueve" se dice "Hoy, a tal fecha, a tal hora, aquí (precisando el lugar), llueve"; si en lugar de decir "aquí hace calor" se dice "aquí (precisando el lugar y el tiempo) yo (precisando a la persona) tengo calor", las frases resultan verdaderas o falsas con independencia de la persona que las enuncia, del lugar y del tiempo.

Desde el punto de vista de los partidarios de la definición clásica de la verdad y de la teoría del reflejo, es totalmente distinta la segunda forma del desacuerdo entre los defensores de la verdad absoluta y quienes sostienen la verdad relativa. Rechazando decididamente el punto de vista del relativismo bajo su forma fundamental, se oponen, con no menos resolución, al punto de vista de los defensores de la verdad absoluta si se trata de la segunda forma del desacuerdo.

Rechacemos la ambigüedad de los términos, causa de malentendidos: el desacuerdo opone en realidad a los partidarios del punto de vista según el cual no puede ser verdadero sino el conocimiento entero, total, bajo todos sus aspectos $y$, por tanto, definitivo, inmutable, y a quienes consideran que la verdad puede y, fuera de ciertas excepciones, debe ser parcial, incompleta $y$, por tanto, variable según se modifique nuestro conocimiento del objeto dado.

Dos problemas se plantean antes que nada: en primer lugar, el empleo de las expresiones "verdad absoluta" y "verdad relativa". El empleo de los términos "absoluto" y "relativo" es comprensible mientras esta calificación haga depender del sujeto, del lugar y del tiempo la verdad o falsedad. Pero esto proviene de la tradición y no de la mejor. ¿Qué significa en este caso preciso la referencia a las circunstancias? Únicamente que la verdad absoluta es inmutable $y$, por tanto, establecida de una vez y para siempre. La verdad parcial, en cambio, siendo variable está ligada a un momento dado. Los fundamentos de estas opiniones son débiles pues la "relatividad" no se refiere aqui al tiempo y al lugar (en tales circunstancias el juicio es verdadero, en tales otras, falso), sino que significa solamente que el conocimiento humano es acumulativo, que se desarrolla en el tiempo y que este desenvolvimiento conlleva una modificación de la forma de las verdades enunciadas a partir de él.

Así, pues, con el fin de evitar los malentendidos que engendran los términos empleados y los deslizamientos lógicos que producen, más vale distinguir, también desde el punto de vista terminológico, los dos pares de contraposiciones: verdad absoluta y relativa, verdad total y parcial.

En segundo lugar, la acepción del término "verdad" difiere en los dos casos. En el primero, de acuerdo con nuestra definición preliminar, "verdad" 
significa "juicio verdadero" o "frase verdadera"; en el segundo el término "verdad" constituye una abreviación de la expresión "conocimiento verdadero". Si estas dos acepciones están estrictamente ligadas entre sí, no coinciden empero enteramente. $\mathrm{El}$ acto de conocer un objeto no debe ser necesariamente un juicio único, sino por el contrario, al reflejar los diversos escorzos, aspectos, fases del desenvolvimiento del objeto, el acto de conocer se compone de numerosos juicios y constituye un próceso. Es evidente que también el juicio puedè modificarse, completarse, tener en cuenta los más diversos aspectos. Es siempre función del desarrollo del conocimiento e influye a su vez en la forma de este conocimiento. Por tanto, también el juicio puede ser un proceso, pero no lo es necesariamente (esto se refiere a las verdades parciales absolutas que, por esta razón, son invariables, como por ejemplo, "dos por dos son cuatro", enunciados históricos tales como "Casimiro el Grande nació en tal fecha"). El conocimiento, por el contrario, es siempre un proceso, dado el carácter infinito de la realidad estudiada (tanto por el número infinito de vínculos entre todos los objetos, cuanto por la infinitud del desarrollo de la realidad).

Hablamos aquí, pues, no sólo de la verdad total y parcial, sino que, desde el punto de vista de su relación con el tiempo, podemos calificarla de absoluta (invariable) y relativa (variable), teniendo en cuenta el hecho de que, si se simplifica el objetivo del conocimiento, se llega en algunos casos a un conocimiento absoluto $\mathrm{y}$, por consiguiente, invariable, de alguna parte o aspecto de la realidad. Esto constituye un argumento suplementario en favor de la distinción propuesta más arriba en materia de terminología.

De lo que hemos dicho, y sin duda es el razonamiento más importante, resulta que el conocimiento y, por tanto, la verdad, es un proceso.

El alcance de esta conclusión es de extrema importancia para la formación de nuestra concepción de la teoría del reflejo; sobre ella, por otra parte, hemos fundado primordialmente nuestra tesis, según la cual la teoría marxista del reflejo no podía construirse sino de acuerdo con el modelo objetivo-activista de la relación cognoscitiva.

$\mathrm{El}$ objeto del conocimiento es infinito: este enunciado se refiere al objeto tanto en el sentido de la realidad en su conjunto cuanto con relación a cada uno de sus fragmentos. La realidad total es, en efecto, infinita, igualmente que sus fragmentos; infinitos son sus vínculos mutuos e infinitas sus modificaciones en el tiempo. El conocimiento de un objeto infinito debe ser, por consiguiente, infinito él también, y debe ser necesariamente un proceso infinito, un proceso que consista en reunir las verdades parciales. Al reunirlas enriquecemos sin cesar nuestro conocimiento y tendemos hacia un limite que es el conocimiento entero, acabado, total y al cual, por tanto, como a los límites de las matemáticas, no puede llegarse en un solo acto de conocimiento y permanece siempre como un proceso infinito tendiente a... 
Engels lo expresó muy bien al desarrollar una de las tesis fundamentales de la gnoseología marxista:

Si la humanidad llegara algún día a no operar sino sobre verdades eternas resultantes del pensamiento, con valor soberano y absoluto derecho a la ver. dad, la humanidad habría llegado a tal situación que todos los males del mundo intelectual se habrían agotado, tanto en acto como en potencia, cumpliéndose así el famoso milagro del innumerable numerado. ${ }^{16}$

El conocimiento es, pues, un proceso infinito, pero un proceso que acumula las verdades parciales que la humanidad ha logrado en las diversas etapas de un desenvolvimiento histórico: extendiendo, restringiendo y superando esas verdades parciales, pero fundándose siempre en ellas y tomándolas como punto de partida de su desarrollo ulterior.

Lo que dijimos más arriba acerca del conocimiento vale igualmente para la verdad. "La verdad" equivale al "juicio verdadero", a la "frase verdadera". En este sentido, la verdad es un proceso: reuniendo verdades parciales, el conocimiento acumula el saber en un proceso infinito que tiende a la verdad total, acabada y, en este sentido, absoluta.

La tesis sobre el conocimiento-proceso y sobre la verdad-proceso es una tesis general y, por tanto, poco concreta. Para poder analizar los diversos dominios de la ciencia, sería necesario disponer de aplicaciones concretas de esta tesis general. Resulta necesario, por tanto, averiguar cuáles son las verdades parciales de las que dispone una rama dada de la ciencia y de qué forma se efectúa el proceso de acercamiento hacia la verdad total y, en ese sentido, absoluta. Las matemáticas, por un lado, y la ciencia de la historia, por el otro, son un buen ejemplo de soluciones extremas a este respecto.

Adam SchafF

(Trad. de Hugo Margain)

International Social SGience Council

European CoOrdination Centre for Research and

DOGUMENTATION IN SOCIAL SCIENCES

16 F. Engels, Anti-Dühring. Ed. Alfred Costes, Paris, 1931, p. 124. 